\title{
Effect of sputtering rate and ion irradiation on the microstructure and magnetic properties of $\mathrm{Ni} / \mathrm{Si}_{3} \mathrm{~N}_{4}$ multilayers
}

\author{
M. Vila and C. Prieto ${ }^{a}$ \\ Instituto de Ciencia de Materiales, Consejo Superior de Investigaciones Científicas, Cantoblanco 28049, \\ Madrid, Spain \\ A. Traverse \\ Laboratoire pour l'Utilisation du Rayonnement Électromagnetique, Centre Universitaire Paris-Sud, BP34, \\ 91898-Orsay Cedex, France \\ R. Ramírez \\ Department Física, Escuela Politécnica Superior, Universidad Carlos III de Madrid, Leganés 28049, \\ Madrid, Spain
}

(Received 1 July 2005; accepted 18 October 2005; published online 6 December 2005)

\begin{abstract}
In order to prepare $\mathrm{Ni}$ clusters embedded in amorphous $\mathrm{Si}_{3} \mathrm{~N}_{4}, \mathrm{Ni}$ and $\mathrm{Si}_{3} \mathrm{~N}_{4}$ layers have been alternatively deposited using sputtering techniques. The nominal Ni layer thickness ranged from 2 to $60 \AA$ and the number of layers was varied accordingly so as to keep the total amount of $\mathrm{Ni}$ constant. Extended x-ray-absorption fine-structure (EXAFS) spectroscopy has been used to study the $\mathrm{Ni}$ clustering as well as the isolated $\mathrm{Ni}$ ions in the silicon nitride matrix. For small $\mathrm{Ni}$ layer thickness, the Ni layer becomes discontinuous and the average size of Ni clusters can be determined. Aiming to modify the Ni surrounding, samples with the thinnest Ni layers have been irradiated with $\mathrm{He}$ and P. The EXAFS results show that the main effect is the removal of the isolated $\mathrm{Ni}$ in the $\mathrm{Si}_{3} \mathrm{~N}_{4}$ matrix. The size evolution of the Ni clusters depends on the type of the irradiating ion. A complete magnetic characterization is presented in order to correlate Ni surrounding with the magnetic properties of Ni clusters. (C) 2005 American Institute of Physics. [DOI: 10.1063/1.2137882]
\end{abstract}

\section{INTRODUCTION}

Small metallic clusters, with a diameter of the order of a few angstroms, exhibit anomalous structural, electronic, and magnetic properties. These properties have been studied to understand their evolution from systems with a few atoms towards the bulk. In particular, the magnetic properties are of interest because of their importance for the design of highly advanced electronic components. ${ }^{1}$ The theoretical proposition that magnetic particles forming small clusters have an average magnetic moment per atom larger than the bulk value has been experimentally confirmed in the case of free particles. $^{2,3}$ Superparamagnetic ${ }^{4}$ behavior or giant magnetoresistance ${ }^{5}$ are some of the magnetic properties that appear in materials with small grain size.

Magnetic systems based on metallic clusters inside wide-band-gap semiconductors, the so-called inhomogeneous magnetic semiconductor (IMS), ${ }^{6}$ have been recently explored because of their close analogy to the diluted magnetic semiconductors ${ }^{7}$ (DMSs) that are excellent candidates for technological applications of spin-dependent electronics (or spintronics). ${ }^{8}$

The determination of the structure of small metal clusters is of paramount importance to understand their correlation with the physical properties of the system. ${ }^{9}$ Cluster formation mechanism and growth processes are also relevant since they determine the cluster size that, in turn, controls the magnetic behavior. From a fundamental point of view, the

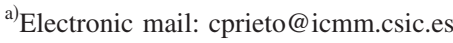

cluster physics must help in the understanding of the magnetic evolution as the cluster size becomes smaller than the thermodynamic size for magnetic domains in the bulk material. Hence, it is of great interest to use preparation techniques in which the cluster size, as well as the distance between clusters, can be controlled.

Granular materials formed by metallic particles embedded in a nonmagnetic matrix can be considered as systems where the magnetic behavior of these small clusters can be modified. By varying some of its features, as for instance the cluster size, interactions between clusters or interactions between matrix and clusters may be changed. It is important to study such systems since, unlike free clusters, the magnetic moment per atom was found smaller than the bulk one in several cases. ${ }^{10,11}$ Sizes and interactions can be controlled by careful tuning of the preparation parameters as well as by exploring different combinations of metallic particles and matrices. An efficient way to tailor the average diameter is varying the ion fluence during the implantation process of immiscible impurities in a target. ${ }^{12,13}$ Sequential sputtering of granular films and nonmagnetic layers allows the monitoring of the distance between the magnetic grains in the growth direction. The structure and morphology of Co grains in $\mathrm{Al}_{2} \mathrm{O}_{3}$ and in $\mathrm{AlN}$ prepared by this technique have already been reported. ${ }^{14,15}$ Yet the distance between the magnetic grains within the granular layer itself is more difficult to control since it depends on wetting properties of one material onto the other. Therefore, it is strongly correlated to the layer thickness.

We have combined here these two approaches, layer 
deposition and ion irradiation, to prepare $\mathrm{Ni}$ particles from thin $\mathrm{Ni}$ films separated by thicker $\mathrm{Si}_{3} \mathrm{~N}_{4}$ layers. The idea is to bring energy to the Ni atoms in a very controlled way, so that previously formed small $\mathrm{Ni}$ clusters can experience a ripening process leading to a very progressive growth. Simultaneously, the intercluster distance is increased. By changing the initial Ni thickness, one can reach model systems with several cluster diameters and intercluster distances where the role of these two parameters on the magnetic behavior can be studied. The $\mathrm{Ni} / \mathrm{Si}_{3} \mathrm{~N}_{4}$ system has been chosen for two reasons. On one hand, in previous studies the authors had gotten oxygen-free silicon nitride films, ${ }^{16,17}$ as well as a precise understanding of the growth of $\mathrm{Ni}$ thin films on $\mathrm{Si}_{3} \mathrm{~N}_{4}$ layers. ${ }^{18}$ On the other hand, we had shown that implantation of Fe and $\mathrm{Co}$ in $\mathrm{Si}_{3} \mathrm{~N}_{4}$ leads to $\mathrm{Fe}$ and Co precipitation. ${ }^{19}$ Our understanding of this behavior makes it possible to predict $\mathrm{Ni}$ precipitation in this matrix.

A prerequisite to investigate cluster properties is a precise structural characterization. The absence of long-range order makes it difficult to use standard technique as x-ray diffraction. The small size is also a limit for transmission electron microscopy. X-ray-absorption spectroscopy is a powerful technique to study nanometric clusters in materials because of its capability to identify the nature of the neighbors, to characterize the atomic arrangement, and to determine the size from the average number of neighbors around a given type of atom. ${ }^{20}$

In this paper, we present a microstructural study of the $\mathrm{Ni} / \mathrm{Si}_{3} \mathrm{~N}_{4}$ system and correlate it to the observed magnetic behavior. The samples were prepared with a multilayer sequence varying the nickel thickness and the deposition rate in order to see the influence on the Ni surrounding. He or P irradiation was used as a tool to modify the Ni neighboring. We took particular care of determining the nature and number of Ni neighbors by x-ray-absorption spectroscopy in the as-prepared state and after irradiation. The aim of the present work is to define a preparation protocol that allows a good control of the cluster size and distance between clusters. Prior to this, determining the Ni layer thickness at the preparation stage and the effect of various irradiation conditions on this initial state is essential.

\section{EXPERIMENT}

$\mathrm{Ni} / \mathrm{Si}_{3} \mathrm{~N}_{4}$ multilayer films were grown by sputtering at room temperature on $\mathrm{Si}(100)$ by using two planar magnetron sources (Angstrom Science) operated by both dc- and rfpower supplies (Huttinger Gmbh.), respectively. Circular targets of $\mathrm{Ni}$ and $\mathrm{Si}$ with a thickness of $3 \mathrm{~mm}$ and 2 in. diameter were mechanically clamped to the water-cooled electrode. The vacuum system provides a residual pressure near 1 $\times 10^{-7}$ mbar. We have used $\mathrm{N}_{2}$ as reactive sputtering gas to deposit silicon nitride from a pure silicon target; a typical deposition rate of $2 \mathrm{~nm} / \mathrm{min}$ is obtained with a rf power of $100 \mathrm{~W}^{16}$ On the other hand, by using Ar as sputtering gas and a dc power from 10 to $30 \mathrm{~W}$, the obtained $\mathrm{Ni}$ growing rate ranges typically from 2 to $7 \mathrm{~nm} / \mathrm{min}$. The samples were made after a large enough presputtering time by using a computer program that controls the exposition time to grow each layer. The program also controls the gas evacuation between both components since different gases are used to grow the metal and the nitride layers.

The compositional characterization of silicon nitride films prepared in this way has been performed by Rutherford backscattering spectroscopy (RBS) and has been reported elsewhere. ${ }^{17}$ Before the sample preparation, the $\mathrm{Ni}$ deposition rate was calibrated by x-ray reflectivity, but in order to determine very precisely the total $\mathrm{Ni}$ amount in all of the samples, RBS experiments have been performed at the Centro Nacional de Aceleradores (Sevilla, Spain) by using the 3 MV tandem ion-beam accelerator. A list of the samples with the preparation conditions and the results is given in Table I.

Within our preparation conditions and for Ni layer average thickness from 2 to $60 \AA$, low-angle x-ray reflectivity spectra do not show a multilayer structure pointing out large roughness.

X-ray-absorption experiments were carried out at Laboratoire pour l'Utilization du Rayonnement Electromagnetique (DCI, XAS13 beam-line) with an electron-beam energy of $1.85 \mathrm{GeV}$ and with an average current of $250 \mathrm{~mA}$. Ni $K$-edge data were obtained by using a fixed exit monochromator consisting of two flat $\mathrm{Si}(111)$ crystals. Signal detection was made by collecting the total electron yield on a biased electrode placed in a $\mathrm{He}$ atmosphere chamber. The sample was maintained at the liquid-nitrogen temperature, ${ }^{21}$ while both x-ray-absorption near-edge structure (XANES) and extended $\mathrm{x}$-ray-absorption fine structure (EXAFS) were recorded.

The XANES spectra were normalized for qualitative comparison purpose. A standard EXAFS analysis was performed by using the VIPER program. ${ }^{22}$ Oscillations were obtained after removing the background by a cubic spline polynomial fitting and EXAFS signal $[\chi(k)]$ was obtained by normalizing the magnitude of the oscillations to the edge jump. The corresponding pseudo-radial-distribution function around $\mathrm{Ni}$ atoms has been obtained weighting by the wave number $[k \chi(k)]$ and multiplying by a hanning window and Fourier transforming. For comparative study, the Fourier transform of EXAFS signal was performed within the same $k$ range. The analysis presented here is based on the fit of the oscillations obtained by back-Fourier transform of the first coordination sphere (between 1.2 and $2.5 \AA$ ). The backscattering amplitude and phase were calculated by the FEFF code (version 6.01) reported by Rehr. ${ }^{23}$ The $S_{0}^{2}$ amplitude loss factor was obtained by using as reference the spectrum of a Ni foil. The EXAFS fit of the first coordination sphere has been made in the standard way and remaining constant the $\Delta k$ range; the number of the fitted parameters is six, being less than that determined by the Stern rule. ${ }^{24}$ Within this analysis, the worst obtained uncertainty in the EXAFS parameters is $\pm 0.02 \AA$ for the fitted distances and $\pm 0.3 \AA$ for the fitted coordination numbers.

Two samples with Ni layer nominal thicknesses of 2 and $4 \AA$ have been ion irradiated at room temperature under conditions summarized in the second column of Table II. The He beam has been delivered by the accélérateur pour la recherche en astrophysique microanalyse et implantation dans les 
TABLE I. Sample characteristics: The samples are noted with their nominal thickness of each individual layer and the number of bilayers as a subindex. The fourth column gives the superficial Ni density from the RBS measurements. EXAFS-obtained parameters: $N_{j}$ is the number of neighbors (the estimated error is \pm 0.3 ), $R_{j}$ is the bond distance (the estimated error is $\pm 0.02 \AA$ ), and $\sigma_{j}^{2}$ is the squared Debye-Waller factor. The amount of the diluted Ni has been obtained from Eq. (5) as a function of the experimentally obtained $N_{j}$ for the $\mathrm{Ni}-\mathrm{N}$ pair $\left(\mathrm{CN}_{\mathrm{Ni}-\mathrm{N}}^{\mathrm{expt}}\right)$, and the cluster average coordination number $\left(\mathrm{ACN} \mathrm{N}_{\text {cluster }}\right)$ has been obtained from Eq. (4) as a function of $N_{j}$ for the $\mathrm{Ni}-\mathrm{Ni}$ pair $\left(\mathrm{CN}_{\mathrm{Ni}-\mathrm{Ni}}^{\text {exp }}\right)$ and the amount of $\mathrm{Ni}$ in clusters.

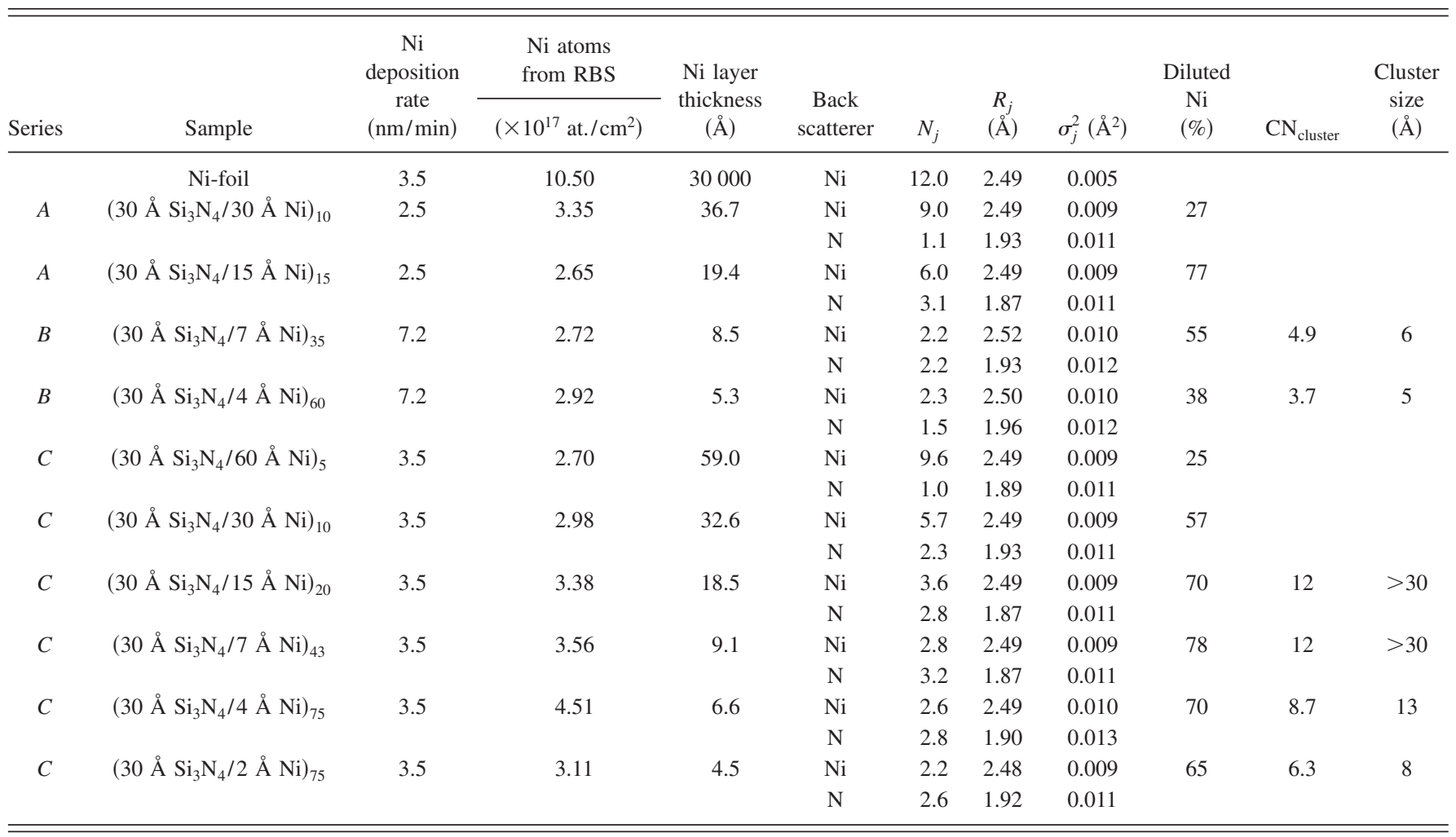

solides (ARAMIS) ${ }^{25}$ whereas the $\mathrm{P}$ one has been delivered by the Implanteur pour la Recherche en Métallurgie et en Astrophysique (IRMA) ${ }^{26}$ According to the TRIM code, ${ }^{27}$ the projected range of the $\mathrm{P}$ ions is about $1500 \AA$, i.e., $60 \%$ of the total sample thickness. He beam is so energetic that all the ions are transmitted through the target and the energy deposited in the sample is at $99.9 \%$ in the form of electronic energy loss. In the case of P irradiation, the electronic energy loss is about $70 \%$. This means that part of the deposited energy is in the form of atomic collisions. Using the TRIM

TABLE II. Characteristics of the irradiations and EXAFS-obtained parameters after the different irradiations.

\begin{tabular}{|c|c|c|c|c|c|c|c|c|c|c|c|}
\hline Sample & Ion & $\begin{array}{c}\text { Incident } \\
\text { energy } \\
(\mathrm{keV})\end{array}$ & $\begin{array}{l}\text { Fluence } \\
\left(\text { at. } / \mathrm{cm}^{2}\right)\end{array}$ & $\begin{array}{l}\text { Flux } \\
(\mathrm{nA})\end{array}$ & $\begin{array}{c}\text { Back } \\
\text { scatterer }\end{array}$ & $N_{j}$ & $\begin{array}{l}R_{j} \\
(\AA)\end{array}$ & $\frac{\sigma^{2}}{\left(\AA^{2}\right)}$ & $\begin{array}{l}\text { Diluted } \\
\mathrm{Ni} \\
(\%)\end{array}$ & $\mathrm{CN}_{\text {cluster }}$ & $\begin{array}{c}\text { Cluster } \\
\text { size } \\
(\AA)\end{array}$ \\
\hline \multirow[t]{9}{*}{$\left(30 \AA \mathrm{Si}_{3} \mathrm{~N}_{4} / 4 \AA \mathrm{Ni}\right)_{75}$} & as prepared & & & & $\mathrm{Ni}$ & 2.6 & 2.49 & 0.010 & 70 & 8.7 & $13 \pm 3$ \\
\hline & & & & & $\mathrm{N}$ & 2.8 & 1.90 & 0.013 & & & \\
\hline & $\mathrm{P}$ & 430 & $6.6 \times 10^{14}$ & 340 & $\mathrm{Ni}$ & 5.2 & 2.46 & 0.007 & 30 & 6.4 & $8 \pm 2$ \\
\hline & & & & & $\mathrm{N}$ & 1.2 & 1.97 & 0.0038 & & & \\
\hline & $\mathrm{P}$ & 430 & $2 \times 10^{15}$ & 500 & $\mathrm{Ni}$ & 5.6 & 2.45 & 0.010 & 28 & 7.8 & $11 \pm 2$ \\
\hline & & & & & $\mathrm{N}$ & 1.1 & 1.98 & 0.008 & & & \\
\hline & $\mathrm{He}$ & 1000 & $3.5 \times 10^{17}$ & 2430 & $\mathrm{Ni}$ & 6.7 & 2.48 & 0.0042 & 16 & 8.5 & $13 \pm 3$ \\
\hline & & & & & $\mathrm{N}$ & 0.6 & 1.98 & 0.0023 & & & \\
\hline & & & & & $\mathrm{Si}$ & 0.4 & 1.77 & 0.001 & & & \\
\hline \multirow[t]{9}{*}{$\left(30 \AA \mathrm{Si}_{3} \mathrm{~N}_{4} / 2 \AA \mathrm{Ni}\right)_{75}$} & as prepared & & & & $\mathrm{Ni}$ & 2.2 & 2.48 & 0.009 & 65 & 6.3 & $8 \pm 2$ \\
\hline & & & & & $\mathrm{N}$ & 2.6 & 1.92 & 0.011 & & & \\
\hline & $\mathrm{P}$ & 430 & $6.6 \times 10^{14}$ & 340 & $\mathrm{Ni}$ & 5.1 & 2.48 & 0.010 & 31 & 7.4 & $9 \pm 2$ \\
\hline & & & & & $\mathrm{N}$ & 1.0 & 1.98 & 0.007 & & & \\
\hline & $\mathrm{P}$ & 430 & $2 \times 10^{15}$ & 500 & $\mathrm{Ni}$ & 5.4 & 2.44 & 0.010 & 25 & 7.2 & $9 \pm 2$ \\
\hline & & & & & $\mathrm{N}$ & 1.2 & 1.98 & 0.009 & & & \\
\hline & $\mathrm{He}$ & 1000 & $3.5 \times 10^{17}$ & 2430 & $\mathrm{Ni}$ & 6.1 & 2.47 & 0.0060 & 6 & 7.6 & $10 \pm 2$ \\
\hline & & & & & $\mathrm{N}$ & 0.2 & 1.98 & 0.0010 & & & \\
\hline & & & & & $\mathrm{Si}$ & 1.0 & 1.72 & 0.0048 & & & \\
\hline
\end{tabular}




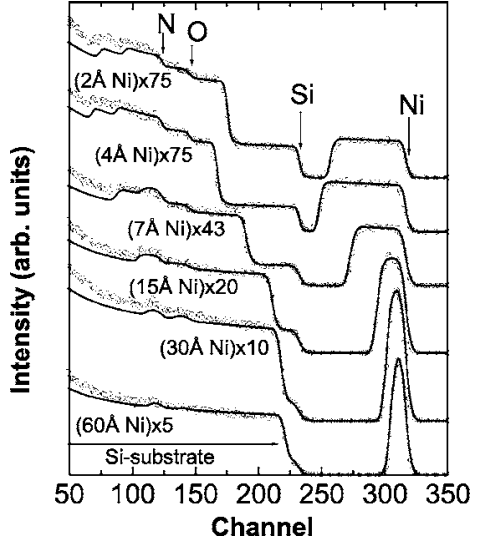

FIG. 1. RBS spectra corresponding to $\mathrm{Si}_{3} \mathrm{~N}_{4} / \mathrm{Ni}$ multilayers. Simulation by the RUMP code is given for comparison (solid line). The chemical symbols and arrows show the signal of each element coming from the film surface. The samples are labeled by the nominal thickness of their Ni layers and the number of bilayers.

estimations, a P fluence of $2 \times 10^{15}$ at. $/ \mathrm{cm}^{2}$ means that, roughly, all the matrix atoms are knocked once. Decreasing the P fluence by a factor of 3 allows one to see the effect of the number of collisions on the $\mathrm{Ni}$ atomic rearrangement. Using two different types of incident ions, $\mathrm{He}$ and $\mathrm{P}$, allows one to see the effect of the energy deposition process.

Magnetization hysteresis loops were measured at 10 and $300 \mathrm{~K}$ in a superconducting quantum interference device (SQUID) magnetometer (MPMS-5S from Quantum Design). Magnetic fields were applied up to $50 \mathrm{kOe}$ in order to saturate the magnetization of the samples. At room temperature, raw measurements show a small negative slope contribution, due to the diamagnetic contribution of the Si substrate. After evaluation by fitting the high-field region of the corresponding $300 \mathrm{~K}$ loop, this Si contribution has been removed from the raw data.

\section{RESULTS}

\section{A. RBS on as-deposited samples}

Figure 1 shows the RBS spectra and their fits performed by the RUMP software. The $\mathrm{Ni}$ and $\mathrm{Si}$ signals are clearly separated with the He energy chosen here and they are identified in the plot. As the whole multilayer thickness is higher, each element signal becomes wider. This is due to the energy loss of the ions that depend on the depth location of the layer where they are backscattered. The Ni layer thickness for each stack calculated after normalizing the RBS-obtained atomic content by the number of $\mathrm{Ni}$ layers and using the Ni bulk density is given in Table I.

\section{B. X-ray absorption spectroscopy on as-deposited samples}

The normalized XANES signals of the $C$-series samples are shown in Fig. 2(a). There is a clear evolution from a signal similar to the Ni bulk one observed for 60 and $30 \AA$ to a different one for the smallest Ni thicknesses. The occurrence of an intense signal at $8350 \mathrm{eV}$ is a fingerprint of $\mathrm{Ni}$ absorbers surrounded by light atoms such as $\mathrm{N}$ or $\mathrm{Si}$ instead of $\mathrm{Ni}$ ones.
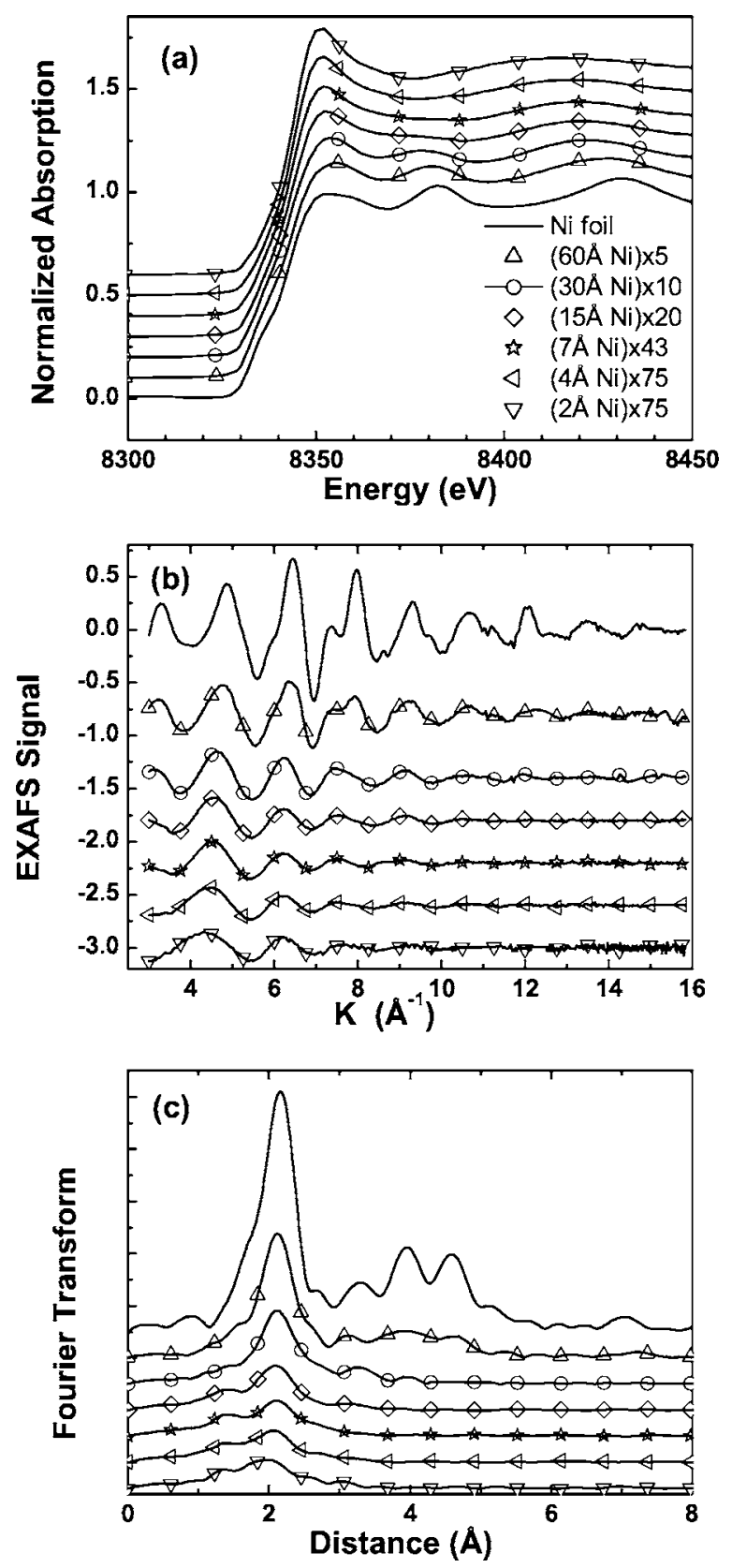

FIG. 2. X-ray-absorption data of $C$ series. (a) Normalized XANES spectra; (b) $\chi(k)$ EXAFS signal; (c) Fourier transform of the $k$-weighted EXAFS signal.

The EXAFS signals for the $C$ series are shown in Fig. 2(b). In parallel with the XANES results, the samples with nominal Ni layer thicknesses of 30 and $60 \AA$ present a clear fcc-like EXAFS structure as in pure bulk Ni. Figure 2(b) shows the Fourier transforms of the $k$-weighted EXAFS signal calculated in the same $k$ interval. The amplitude of the peak located at $2 \AA$ (distance not corrected from phase shift) decreases with the nominal Ni thickness. The signal at larger distances disappears indicating that long-range atomic order is lost in the samples with nominal Ni thickness less than 30 $\AA$. Moreover, a small peak appears at distances shorter than 2 $\AA$ (distance not corrected from phase shift).

In the fit, we have considered a $\mathrm{Ni}-\mathrm{Ni}$ contribution that accounts for the intense peak located at $2 \AA$ in the Fourier transform. Two possible pairs have been taken into account 


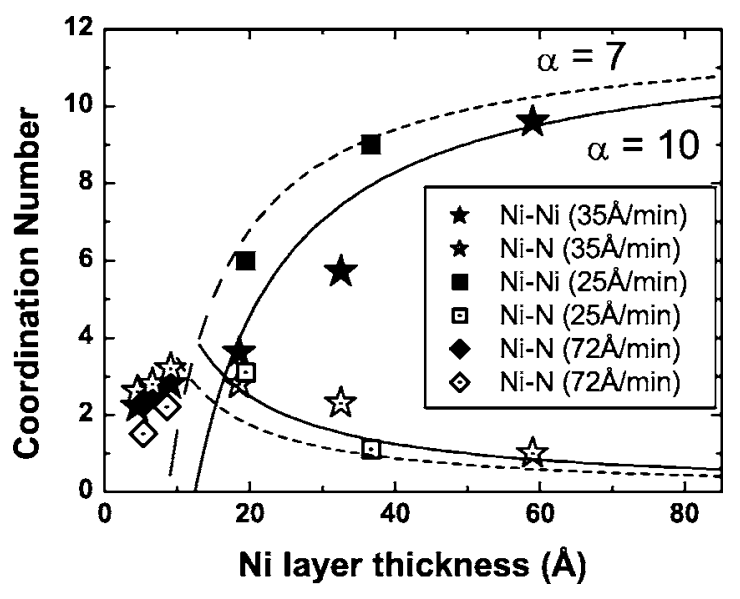

FIG. 3. Coordination number as a function of layer thickness. The symbols are the EXAFS results obtained for $\mathrm{Ni}-\mathrm{Ni}$ and $\mathrm{Ni}-\mathrm{N}$ pairs. The lines are calculated as indicated in the text (solid line for $\alpha=10$ and dashed line for $\alpha=7)$. Three series with different deposition rates are presented. The stars, squares, and diamonds correspond to 35,25 , and $72 \AA / \mathrm{min}$, respectively. The full and open symbols represent the $\mathrm{Ni}-\mathrm{Ni}$ and $\mathrm{Ni}-\mathrm{N}$ coordination numbers.

for explaining the peak located at a short distance: $\mathrm{Ni}-\mathrm{N}$ and $\mathrm{Ni}-\mathrm{Si}$. The fitting procedure shows that the contribution of the Ni-Si pair is not significant, and that the peak must be ascribed to $\mathrm{Ni}-\mathrm{N}$ bonds at a distance near $1.9 \AA$.

Table I presents the EXAFS results for the three series of stacks in the as-deposited state where the effect of Ni layer thickness and sputtering rate is analyzed. $C$ series will provide the focus of discussions since it covers a larger range of $\mathrm{Ni}$ layer nominal thickness. A decrease of the Ni-Ni coordination number $(\mathrm{CN})$ is observed for the smaller $\mathrm{Ni}$ layer thickness samples together with an increase of the number of $\mathrm{N}$ neighbors. Figure 3, where the obtained $\mathrm{CN}$ is plotted for the three series, summarizes the effect of $\mathrm{Ni}$ thickness and deposition rate on the Ni surrounding that will be discussed later.

\section{X-ray absorption spectroscopy on irradiated samples}

Two samples of the $C$ series with the thinnest Ni layers have been ion beam irradiated. Figure 4 shows the normalized XANES spectra of the irradiated samples compared with the as-grown $\left(30 \AA \mathrm{Si}_{3} \mathrm{~N}_{4} / 4 \AA \mathrm{Ni}\right)_{75}$ and $\left(30 \AA \mathrm{Si}_{3} \mathrm{~N}_{4} / 2 \AA \mathrm{Ni}\right)_{75}$. For both samples, the evolution towards an XANES closer to the fcc crystallographic Ni bulk structure is clear. Figure 5 shows the corresponding Fourier transforms obtained for the irradiated samples. It can be observed that for some irradiation conditions, nickel lose the amorphouslike character and, for all of them, the EXAFS signal increases strongly, indicating a growing of the clusters size.

Table II summarizes the results of the fit where $\mathrm{Ni}-\mathrm{Ni}$, $\mathrm{Ni}-\mathrm{N}$, and $\mathrm{Ni}-\mathrm{Si}$ contributions have to be taken into account. The Ni-Ni number increases, but the more relevant fact is the reduction of $\mathrm{Ni}$ coordinated to $\mathrm{N}$ atoms.
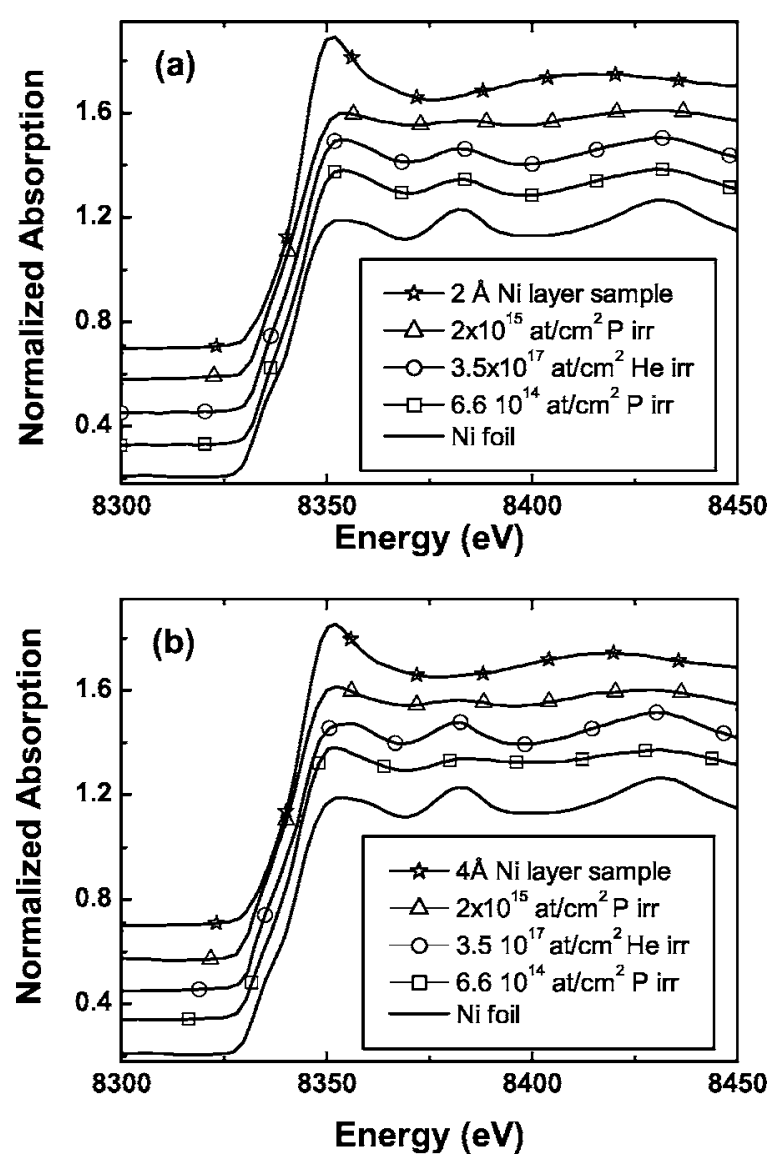

FIG. 4. Normalized XANES spectra of the irradiated samples. (a) Sample of $4 \AA ̊$ Ni layer thickness; (b) sample of $2 \AA$ Ni layer thickness.

\section{Magnetic characterization}

Figure 6 shows the magnetic hysteresis loops measured at 10 and $300 \mathrm{~K}$ and normalized to the volume of $\mathrm{Ni}$ present in the samples. Figure 6(a) shows the data $\left(30 \AA \mathrm{Si}_{3} \mathrm{~N}_{4}\right.$ / $60 \AA \mathrm{Ni})_{5}$ and $\left(30 \AA \mathrm{Si}_{3} \mathrm{~N}_{4} / 15 \AA \mathrm{Ni}\right)_{20}$ samples of the $C$ series in the as-deposited state for the two temperatures. The most salient feature is the positive slope in the high-field regions for both samples at $10 \mathrm{~K}$; it may be due to the paramagnetic behavior of the isolated $\mathrm{Ni}$ in the $\mathrm{Si}_{3} \mathrm{~N}_{4}$ matrix (so-called diluted nickel) since, on the one hand, this effect is not present at $300 \mathrm{~K}$ (where paramagnetic susceptibility should drop by a factor of 30). On the other hand, the ratio between the slopes for both samples in Fig. 6, which is 2.7 [higher for sample $\left(30 \AA \mathrm{Si}_{3} \mathrm{~N}_{4} / 15 \AA \mathrm{Ni}\right.$ ) 20 ], is in agreement with the amount of diluted nickel from the EXAFS data (as summarized in Table I) that allows a ratio of 2.8 between diluted nickel for both samples.

The inset illustrates the low-field region where the coercivity can be observed. Thus the overall magnetic cycle for both samples corresponds to metallic ferromagnetic nickel plus paramagnetic nickel diluted in the matrix. Saturation of the magnetization $M_{s}$, obtained in the range of $10 \mathrm{kOe}$, decreases strongly from 10 to $300 \mathrm{~K}$, a behavior very different from the one of pure Ni that has a Curie temperature of 627 $\mathrm{K}$. The ratio between $M_{s}$ at $10 \mathrm{~K}$ for both samples is 1.95 ( $M_{s}$ being higher for the $60 \AA \mathrm{Ni}$ layer sample); this value is also in agreement with the amount of metallic nickel as sum- 


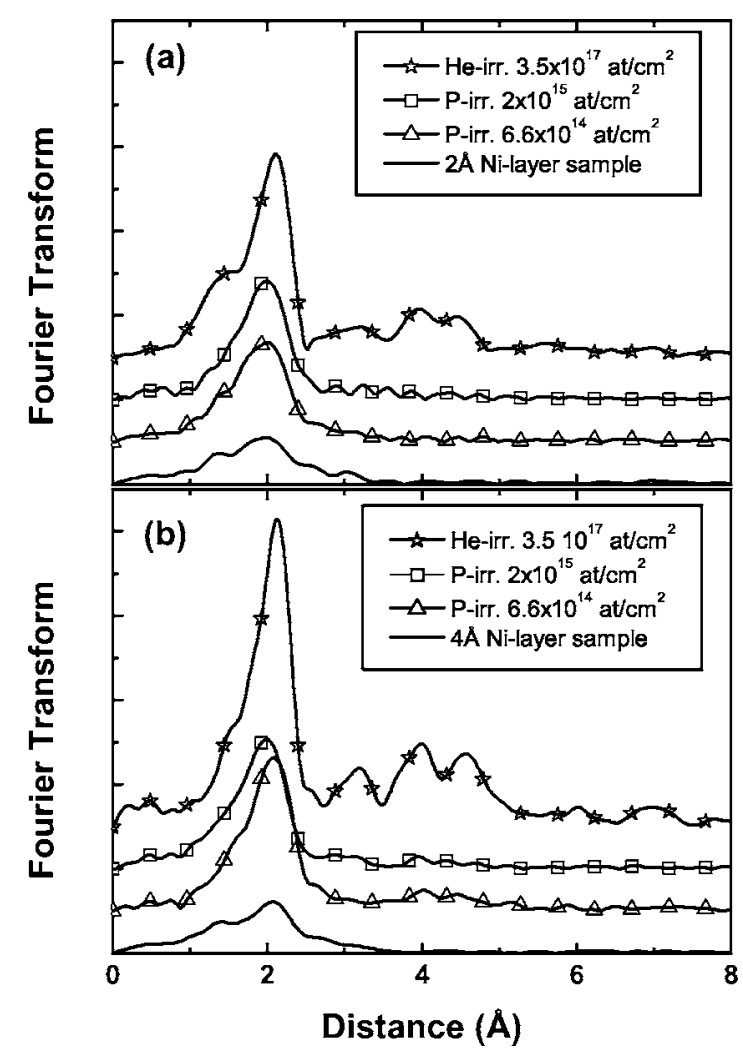

FIG. 5. Fourier transform magnitude obtained for the irradiated samples. (a) Sample of $4 \AA$ Ni layer thickness; (b) sample of $2 \AA$ Ni layer thickness.

marized in Table I that is 1.99 . It must be mentioned that $M_{s}$ at $10 \mathrm{~K}$ is only $184 \mathrm{emu} / \mathrm{cm}^{3}$ (taking into account the amount in the metallic form) instead of $521 \mathrm{emu} / \mathrm{cm}^{3}$ as in bulk Ni. Note that a positive slope is present at the high-field region for the sample with Ni layers that are $15 \AA$ thick.

The magnetic cycles for $\left(30 \AA \mathrm{Si}_{3} \mathrm{~N}_{4} / 4 \AA \mathrm{Ni}\right)_{75}$ and $\left(30 \AA \mathrm{Si}_{3} \mathrm{~N}_{4} / 2 \AA \mathrm{Ni}\right)_{75}$ are plotted in Fig. $6(\mathrm{~b})$. At $10 \mathrm{~K}$, the $\left(30 \AA \mathrm{Si}_{3} \mathrm{~N}_{4} / 4 \AA \mathrm{Ni}\right)_{75}$ sample presents a small ferromagnetic contribution, but it is not so clear for the $\left(30 \AA \mathrm{Si}_{3} \mathrm{~N}_{4} / 2 \AA \mathrm{Ni}\right)_{75}$ one [inset of Fig. 6(b)]. A positive big slope is seen on the signal at high fields and low temperature. The thinner the Ni layer, the bigger the observed slope contribution. Such behavior, as mentioned above, could be ascribed to $\mathrm{Ni}$ atoms in a paramagnetic state.

Figure 7 shows the magnetic cycles at $10 \mathrm{~K}$ for three different states of samples: as prepared, He irradiated, and $\mathrm{P}$ irradiated (fluence of $6.6 \times 10^{14}$ at. $/ \mathrm{cm}^{2}$ ). The magnetization versus field shows the disappearance of the positive slope when irradiation is performed with $\mathrm{He}$ whereas it is still faintly present when irradiation is performed with $\mathrm{P}$.

\section{INTERPRETATION AND DISCUSSION}

The analysis of XAS shows that the Ni atomic surrounding is different in the as-prepared state when the deposition rate and (or) the layer thickness are changed. The fact that the samples deposited with two different rates present different $\mathrm{Ni}$ coordination numbers for the same nominal thickness (see Fig. 3) is ascribed to changes in film roughness. In Sec. IV A, we will interpret this in terms of layer morphology. In Sec. IV B, the effect of the energy given by ion irradiation on
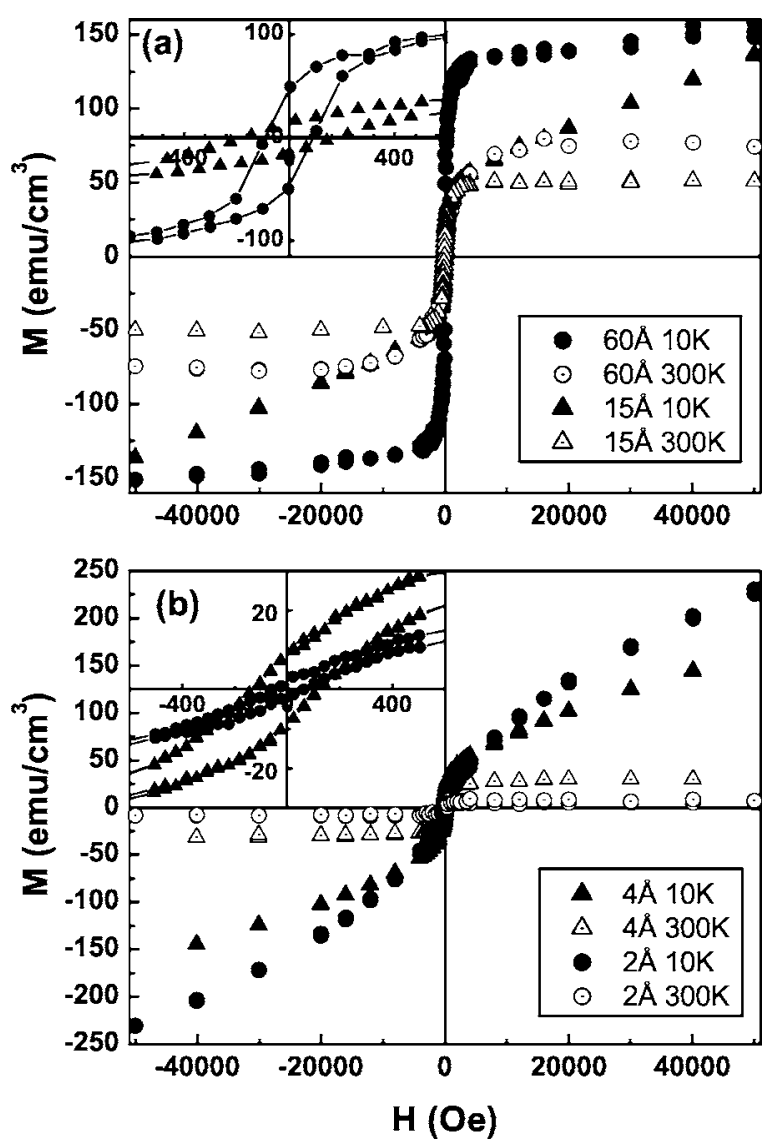

FIG. 6. (a) Room temperature and $10 \mathrm{~K}$ measurements of hysteresis loops of $\left(30 \AA \mathrm{Si}_{3} \mathrm{~N}_{4} / 60 \AA \mathrm{Ni}\right)_{5}$ and $\left(30 \AA \mathrm{Si}_{3} \mathrm{~N}_{4} / 15 \AA \mathrm{Ni}\right)_{20}$ samples. (b) Hysteresis loops of $\left(30 \AA \mathrm{Si}_{3} \mathrm{~N}_{4} / 4 \AA \mathrm{Ni}\right)_{75}$ and $\left(30 \AA \mathrm{Si}_{3} \mathrm{~N}_{4} / 2 \AA \mathrm{Ni}\right)_{75}$ samples.

the layer morphology is addressed. The magnetic properties of the as-prepared and irradiated systems are discussed in Sec. IV C.

\section{A. Ni layer morphology in the as-deposited state: Effect of deposition velocity}

As demonstrated by XAS, $\mathrm{Ni}$ is bonded to other atoms than $\mathrm{Ni}$ ones whatever the layer thickness. Bonds with atoms of the matrix are due to interface effects. It can be easily calculated $^{28}$ that for a perfect continuous $\mathrm{Ni}$ layer with a thickness $t$ and with an interatomic plane distance $e$, the $\mathrm{CN}_{\mathrm{Ni}-\mathrm{Ni}}$ coordination number is given by

$$
\mathrm{CN}_{\mathrm{Ni}-\mathrm{Ni}}=\mathrm{CN}_{\mathrm{Ni}-\mathrm{Ni}}^{\text {bulk }}(1-e / 2 t),
$$

where $\mathrm{CN}_{\mathrm{N}}^{\mathrm{bu}-\mathrm{Ni}}$ is the coordination number for the bulk fcc phase $\left(\mathrm{CN}_{\mathrm{Ni}-\mathrm{Ni}}^{\mathrm{bulk}}=12\right)$ and the $\mathrm{Ni}$ atoms located at the layer/ matrix interface have a $3 / 4$ fraction of the $\mathrm{CN}$ of bulk atoms. Taking $t=60 \AA$ and $e=2 \AA$, Eq. (1) provides $\mathrm{CN}_{\mathrm{Ni}-\mathrm{Ni}}=11.8$, far from the value of 9.6 given in Table I and out of the experimental uncertainty. Moreover, in such a configuration a number of matrix atom neighbors should be $\left(\mathrm{CN}_{\mathrm{Ni}-\mathrm{N}}^{\mathrm{bulk}} e / 2 t\right)=0.016 \times \mathrm{CN}_{\mathrm{Ni}-\mathrm{N}}^{\text {bulk }}$, i.e., much smaller than 1.0 as in Table I. The finite thickness effect can be detected by XAS only for $t<20 \AA$. In addition, the $M_{s}$ value at low temperature for the sample with $\mathrm{Ni}$ that is $60 \AA$ thick is only $30 \%$ of the bulk one and there is a strong $M_{s}$ decrease with temperature. These facts are in favor both of a discontinuous 

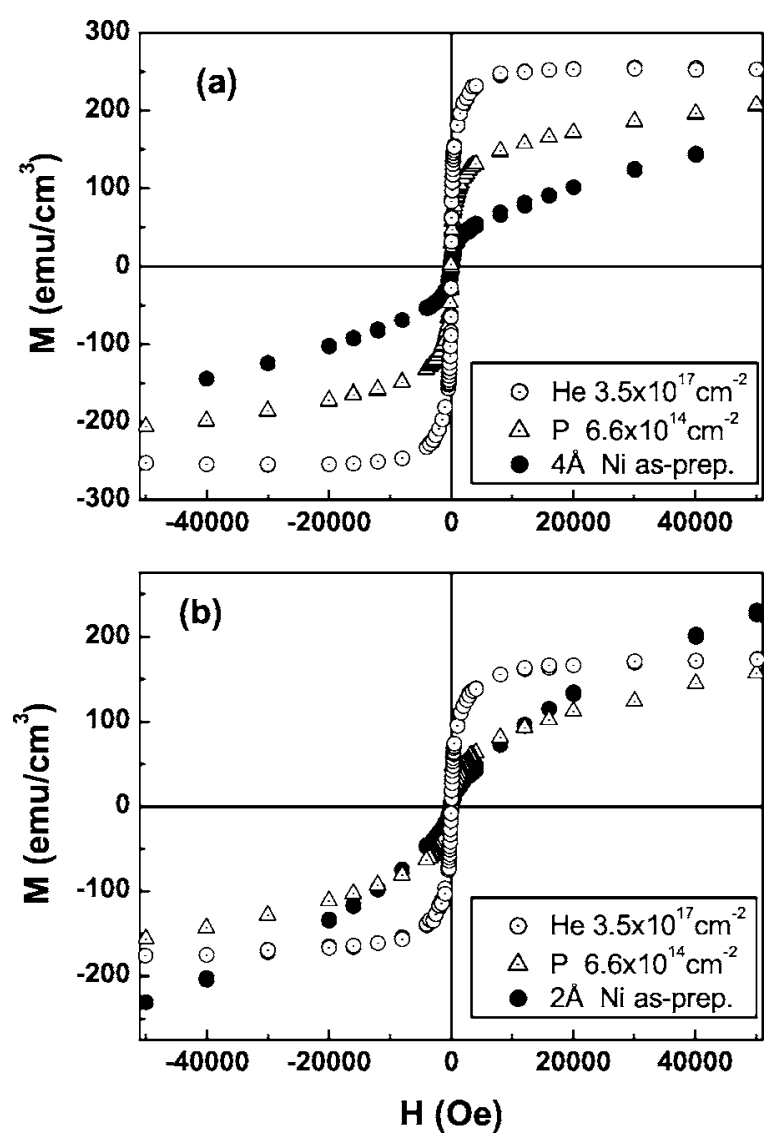

FIG. 7. Hysteresis loops at $10 \mathrm{~K}$ for three different states of $\left(30 \AA \mathrm{Si}_{3} \mathrm{~N}_{4} / 4 \AA \mathrm{Ni}\right)_{75}$ and $\left(30 \AA \mathrm{Si}_{3} \mathrm{~N}_{4} / 2 \AA \mathrm{Ni}\right)_{75}$ samples: as prepared, He irradiated, and P irradiated (fluence of $6.6 \times 10^{14}$ at. $/ \mathrm{cm}^{2}$ ).

$\mathrm{Ni}$ layer where metallic $\mathrm{Ni}$ grains are formed and of $\mathrm{Ni}$ atoms (or ions) in a nonferromagnetic state. Note that XAS has detected $\mathrm{Ni}$ atoms surrounded by $\mathrm{N}$ ones that should not be ferromagnetic.

To go deeper in the layer characterization, one can consider, in a first step, large roughness so that parts of the film are much thinner than others. The fact that different series present different $\mathrm{Ni}$ coordination numbers for the same nominal thickness (see Fig. 3) can be ascribed to changes in film roughness and furthermore in the Ni layer morphology induced by the deposition rate.

To study finite thickness effects together with the influence of roughness on the Ni surrounding, we have calculated the average $\mathrm{CN}$ of $\mathrm{Ni}$ atoms taking into account both parameters. We used a model that is based on a $1 / 4$ reduction of the neighbor number for the atoms placed at the boundary of the layer. A simplified version of this model has been used previously to study $\mathrm{Si} / \mathrm{Ge}$ superlattices ${ }^{28}$ in order to obtain information about the interfaces by studying the $\mathrm{Ge}-\mathrm{Si}$ coordination. The surface atoms having one-half of the $\mathrm{CN}$ of bulk atoms, the average $\mathrm{CN}$ expression can be easily obtained as

$$
\mathrm{CN}_{(\mathrm{Ni}-\mathrm{Ni})}=\mathrm{CN}_{\mathrm{Ni}-\mathrm{Ni}}^{\text {bulk }}\left(1-\frac{\alpha d}{2 t}\right)=12\left(1-\frac{\alpha d}{2 t}\right),
$$

where $d$ is the first neighbor distance. In this expression, $\alpha(\alpha>1)$ is a parameter that takes into account the film roughness by introducing a $t / \alpha$ thickness smaller than the nominal one $(t)$. Thus, the higher the $\alpha$ value, the larger the amount of atoms at the interface; as expected when the layer is rougher. Moreover, we can estimate the number of $\mathrm{Ni}$ atoms located at the film/matrix interface that can be coordinated with $\mathrm{N}$ atoms from the $\mathrm{Si}_{3} \mathrm{~N}_{4}$ film below:

$$
\mathrm{CN}_{(\mathrm{Ni}-\mathrm{N})}=\frac{1}{4} \mathrm{CN}_{\mathrm{Ni}-\mathrm{N}}^{\text {bulk }}\left(\frac{2 \alpha d}{t}\right)=2 \frac{\alpha d}{t} .
$$

$\mathrm{CN}_{\mathrm{Ni}-\mathrm{N}}^{\text {bulk }}$ is the coordination number of $\mathrm{Ni}$ bonded to nitrogen in a bulk state where it is in substitution of Si. Consequently, we have taken $\mathrm{CN}_{\mathrm{Ni}-\mathrm{N}}^{\text {bulk }}$ equal to 4 because this is the silicon coordination in the silicon nitride matrix.

Figure 3 shows the calculated curves that correlate the $\mathrm{CN}$ with film thickness. The $\alpha$ values are obtained by calculating the $\mathrm{Ni}-\mathrm{Ni} \mathrm{CN}$ that fits the $\mathrm{CN}$ value for the thickest sample of the series. The obtained $\alpha$ value is used to calculate the $\mathrm{Ni}-\mathrm{Ni}$ and $\mathrm{Ni}-\mathrm{N} \mathrm{CN}$ curves. The agreement is good in the range from 20 to $60 \AA$ for values of $\alpha=7$ and $\alpha=10$ obtained for the $A$ and $C$ series, respectively. Roughness increases when the deposition rate increases. This is in agreement with the idea that layers grow in a more perfect way when atoms have enough time to diffuse to well-ordered crystallographic sites.

As a first approximation $t / \alpha$ can be considered as an effective thickness. When $t / \alpha$ becomes of the order of the atomic plane distance the layer does not exist anymore. For an atomic plane distance of $2 \AA$, one can calculate the thinnest thickness $t^{\prime}$ for which continuity is ensured, i.e., when $t^{\prime} / \alpha=2$. For $\alpha=10$, one finds $t^{\prime}=20 \AA$, and for $\alpha=7$, one finds $t^{\prime}=14 \AA$. The nominal thickness for which the Ni film is no longer continuous depends on the sputtering rate. Actually, the thinnest samples of the $C$ series and those of the $B$ series with thickness smaller than $10 \AA$ display coordination numbers that depart from the calculated curve in Fig. 3. Below this thickness the Ni film must be considered as formed of dispersed metallic clusters.

In the cluster regime, it is possible to estimate the cluster size from the EXAFS data using a model similar to that proposed for spherical clusters by Boroswki. ${ }^{29}$ By considering a small cluster made of a $\mathrm{Ni}$ core surrounded by a shell formed by a $\mathrm{Ni}-\mathrm{N}$ phase, one cannot reproduce the $\mathrm{Ni}-\mathrm{Ni}$ and $\mathrm{Ni}-\mathrm{N}$ coordination versus the cluster diameter as it is explained in the Appendix. Another hypothesis has to be considered. The proportion of $\mathrm{N}$ neighbors being much larger in these samples than in the model (see Table I), the existence of $\mathrm{Ni}$ atoms diluted in the $\mathrm{Si}_{3} \mathrm{~N}_{4}$ matrix in addition to those in metallic clusters has to be taken into account. Such diluted $\mathrm{Ni}$ atoms contribute with a paramagnetic signal that increases and becomes appreciable at low temperatures, a picture that agrees well with the magnetic curves recorded for 2 and $4 \AA$ of Ni [see Fig. 6(b)]. Within this model, the experimentally obtained $\mathrm{Ni}-\mathrm{Ni} \mathrm{CN}$ can be expressed as 


$$
\mathrm{CN}_{\mathrm{Ni}-\mathrm{Ni}}^{\text {expt }}=\frac{\mathrm{CN}_{\text {cluster }} \times[\mathrm{Ni}]_{\text {cluster }}}{[\mathrm{Ni}]_{\text {tot }}}=\frac{\mathrm{ACN}_{\text {cluster }} \times[\mathrm{Ni}]_{\text {cluster }}}{[\mathrm{Ni}]_{\text {cluster }}+[\mathrm{Ni}]_{\text {diluted }}},
$$

being $\mathrm{ACN}_{\text {cluster }}$ as the average coordination number for atoms forming the clusters and $[\mathrm{Ni}]_{x}$ as the atomic Ni concentration in the different aggregation states. Following the same model, the experimentally obtained $\mathrm{Ni}-\mathrm{N}$ coordination number is expressed as

$$
\mathrm{CN}_{\mathrm{NiN}}^{\text {expt }}=\frac{\mathrm{CN}_{\mathrm{Ni}-\mathrm{N}} \times[\mathrm{Ni}]_{\text {diluted }}}{[\mathrm{Ni}]_{\text {tot }}}=\frac{\mathrm{CN}_{\mathrm{Ni}-\mathrm{N}} \times[\mathrm{Ni}]_{\text {diluted }}}{[\mathrm{Ni}]_{\text {cluster }}+[\mathrm{Ni}]_{\text {diluted }}},
$$

where $\mathrm{CN}_{\mathrm{Ni}-\mathrm{N}}=4$, in order to take into account that Ni substitutes $\mathrm{Si}$ in the silicon nitride matrix.

Equation (5) allows an estimation of the amount of diluted $\mathrm{Ni}$ as a function of $\mathrm{CN}_{\mathrm{Ni}-\mathrm{N}}^{\text {expt }}$ (which is the experimentally obtained Ni-N coordination that in Table I is called $N_{j}$ for the Ni-N pair). The cluster average coordination number $\left(\mathrm{ACN}_{\text {cluster }}\right)$ can be obtained by Eq. (4) from $\mathrm{CN}_{\mathrm{Ni}-\mathrm{Ni}}^{\text {expt }}$ (which is the experimentally obtained $\mathrm{Ni}-\mathrm{Ni}$ coordination that in Table I is called $N_{j}$ for the Ni-Ni pair) and the amount of Ni in clusters (that is the complementary of diluted $\mathrm{Ni}$ ).

The Ni cluster average coordination number $\left(\mathrm{ACN}_{\text {cluster }}\right)$ is a function of their radius; it has been represented in Fig. 9(b) as a spherical cluster without any covering shell; that corresponds to the model proposed by Boroswki. ${ }^{29}$ From the EXAFS-obtained CNs, it is possible to determine the cluster size of the samples with smaller Ni layer thickness. First, by using Eq. (5), one can evaluate the concentration of diluted $\mathrm{Ni}$ by comparing the obtained $\mathrm{Ni}-\mathrm{N}$ neighbor number with 4 (this is the nitrogen coordination for a silicon substituted by $\mathrm{Ni}$ in the silicon nitride compound). After that, Eq. (4) provides the average $\mathrm{CN}$ inside the metallic cluster $\left(\mathrm{CN}_{\text {cluster }}\right)$. This value is different from the bulk $\mathrm{CN}$ only because of the finite-size effect; now it is possible to evaluate the cluster size by using the curve of Fig. 9 for a noncovering shell. Those results are given in Table I.

From this hypothesis we can conclude that, for our deposition conditions, $10 \AA$ is the limit of the continuous layer. In other words, it seems to correspond to the percolation limit of the clusters to form a continuous layer in the $\mathrm{Ni} / \mathrm{Si}_{3} \mathrm{~N}_{4}$ multilayer system for a given amount of silicon nitride.

XAS identified $\mathrm{N}$ neighbors for $\mathrm{Ni}$ in the studied samples. This is unexpected from the thermodynamical point of view since the $\mathrm{Ni}-\mathrm{N}$ bonds are much less favored than the $\mathrm{Ni}-\mathrm{Si}$ ones. Indeed this is a different situation from what has been observed in implanted $\mathrm{Co} / \mathrm{Si}_{3} \mathrm{~N}_{4}$ where $\mathrm{Co}-\mathrm{Co}$ and $\mathrm{Co}-\mathrm{Si}$ bonds were identified. No $\mathrm{Co}-\mathrm{N}$ bonds were detected and the $\mathrm{Co}-\mathrm{Si}$ bonds result from $\mathrm{Co}$ atoms at the surface of Co clusters. ${ }^{19}$ In the case of the $\mathrm{Co} / \mathrm{AlN}$ multilayer system, Co has $\mathrm{Al}$ neighbors and not $\mathrm{N}$ ones. Kawamura et al. ${ }^{30}$ investigated the formation process for $\mathrm{Ni}_{x} \mathrm{~N}$ compounds by reactive sputtering. They succeeded in forming those phases with $x=2$ or 3 . In the case of our samples, one may think that when the $\mathrm{Ni}$ atoms reach the previously deposited $\mathrm{Si}_{3} \mathrm{~N}_{4}$ layer, there is a probability to interact with it by substituting a $\mathrm{Si}$ atom. From our experience, the film surface of $\mathrm{Si}_{3} \mathrm{~N}_{4}$ is very reactive when the samples have not been exposed to air passivation, for instance, it is not possible to deposit metallic electrodes (not even with gold) over a fresh nitride layer becoming a surface insulator, which agrees with a diffusion of metals inside the silicon nitride film.

\section{B. Effect of energy irradiation on layer morphology}

Energy deposition strongly modifies the microstructure and consequently the magnetic behavior of the irradiated samples. The EXAFS analysis detects a decrease of the number of $\mathrm{Ni}$ atoms surrounded by $\mathrm{N}$ neighbors. That is not surprising since this surrounding is thermodynamically unstable. Hence, inputing some energy helps the atoms located in unstable sites to move towards more stable sites. Within the irradiation conditions used here, only $60 \%$ of the sample is irradiated by $\mathrm{P}$ ions. The reduction from about $65 \%-70 \%$ initially diluted $\mathrm{Ni}$ atoms to about $25 \%-30 \%(\approx 40 \%$ of $65 \%-70 \%$ ) could correspond to the irradiated part of the sample only. Yet there is no difference in the number of relocated $\mathrm{Ni}$ atoms when the $\mathrm{P}$ fluence is changed by a factor of 3. One can think that when energy is provided by nuclear collisions, $\mathrm{Ni}$ atoms extracted from unstable sites can be knocked on another time and replaced in substitution of Si. On the contrary, He irradiation is more efficient in the relocation process. Since He irradiation means electronic stopping power only, hence electronic excitations, the relevant parameter is the energy of the He irradiation. The process might be here a charge effect that helps in detrapping the $\mathrm{Ni}$ atoms from their unstable $\mathrm{N}$ neighboring. A better efficiency of electronic excitations was observed recently during irradiation of silicon-based gels containing diluted metallic ions that precipitate under this energy deposition process. ${ }^{31}$

Taking into account the same model as in the above calculations, it is possible to obtain the cluster sizes for the irradiated samples. We observe that the average cluster size is not strongly modified and its evolution stays more or less within the experimental uncertainty. There is a tendency to get larger clusters after He irradiation than after P irradiation. It is more evident from the Fourier transforms that a better crystallographic order is reached for He-irradiated samples. It is intriguing to see that $\mathrm{P}$ irradiation leads to a size decrease for $\mathrm{Ni}$ that is $4 \AA$ and an increase for $\mathrm{Ni}$ that is $2 \AA$. The explanation could be found in the different $\mathrm{Ni}$ concentration in both samples that, being higher in the $4 \AA$ Ni layer sample, inhibit the cluster growing because clusters might be too close from the others. The Ni atoms detrapped from the $\mathrm{Si}$ sites are able to precipitate, thus the number of clusters increases instead of a growing of the former ones.

Assuming that the Ni clusters are spherical and distributed on a square lattice within a single layer, a very crude representation of the thinnest samples before and after $\mathrm{He}$ irradiation can be proposed. The cluster volumes $V$ are calculated from the average size deduced from the EXAFS analysis, the average size being considered as the diameter. The intercluster distances $l$ are deduced using the following formula: 
TABLE III. Coordination number obtained from the EXAFS analysis $\left(\mathrm{CN}_{\text {cluster }}\right)$, intercluster distance $(l)$, number of cluster/ $\mathrm{cm}^{2}$, ratio between intercluster and diameter distances $(l / D)$, raw magnetization saturation measured at $10 \mathrm{~K}\left(M_{s}\right)$, corrected $M_{s}$ after normalization by aggregated $\mathrm{Ni}$, average cluster diameter extracted from the Langevin distribution fits $\left(D_{\text {Langevin }}\right)$, and average coordination number $\left(\mathrm{CN}_{\text {magnetic }}\right)$ obtained from the distributions.

\begin{tabular}{|c|c|c|c|c|c|c|c|c|c|}
\hline Sample & & $\left(\mathrm{CN}_{\text {cluster }}\right)$ & $\begin{array}{c}1 \\
(\AA)\end{array}$ & $\begin{array}{c}\text { Number of } \\
\text { clusters } \\
\left(\mathrm{cm}^{-2}\right)\end{array}$ & $l / D$ & $\begin{array}{c}\text { Raw } \\
M_{3} \\
\left(\mathrm{emu} / \mathrm{cm}^{3}\right)\end{array}$ & $\begin{array}{c}\text { Corrected } M_{3} \\
\left(\mathrm{emu} / \mathrm{cm}^{3}\right)\end{array}$ & $D_{\text {Langevin }}(\AA)$ & $\mathrm{CN}_{\text {magnetic }}$ \\
\hline$\left(30 \AA \mathrm{Si}_{3} \mathrm{~N}_{4} / 60 \AA \mathrm{Ni}\right)_{5}$ & & & & & & 150 & 200 & & \\
\hline$\left(30 \AA \mathrm{Si}_{3} \mathrm{~N}_{4} / 15 \AA \mathrm{Ni}\right)_{20}$ & & & & & & 60 & 200 & & \\
\hline$\left(30 \AA \mathrm{Si}_{3} \mathrm{~N}_{4} / 4 \AA \mathrm{Ni}\right)_{75}$ & as prepared & 8.7 & 24 & $1.6 \times 10^{14}$ & 1.8 & 60 & 200 & 13 & 6 \\
\hline \multirow{5}{*}{$\left(30 \AA \mathrm{Si}_{3} \mathrm{~N}_{4} / 2 \AA \mathrm{Ni}\right)_{75}$} & $\mathrm{P}$ & 6.4 & 7.6 & $1.6 \times 10^{14}$ & 1 & 150 & 214 & 20 & 8.2 \\
\hline & $\mathrm{He}$ & 8.5 & 14 & $4.4 \times 10^{14}$ & 1.1 & 250 & 300 & 24 & 8.7 \\
\hline & as prepared & 6.3 & 13 & $5.4 \times 10^{14}$ & 1.6 & 80 & 230 & 11 & 5.8 \\
\hline & $\mathrm{P}$ & 7.4 & 11 & $7.5 \times 10^{14}$ & 1.2 & 80 & 116 & 14 & 7 \\
\hline & $\mathrm{He}$ & 7.6 & 11 & $7.4 \times 10^{14}$ & 1.1 & 170 & 180 & 20 & 8.2 \\
\hline
\end{tabular}

$$
l=\sqrt{\frac{V}{t_{\text {true }}}},
$$

where $t_{\text {true }}$ takes into account the amount of $\mathrm{Ni}$ atoms as measured by RBS in one Ni layer and corrected by the percentage of nondiluted Ni. The number of clusters $/ \mathrm{cm}^{2}$ is obtained from the number of nondiluted $\mathrm{Ni}$ atoms with $t_{\text {true }}$ and the bulk Ni density divided by the volume $V$. All these data are presented in Table III. One sees that in the asprepared state, smaller clusters exist in the $2 \AA \mathrm{Ni}$ layers but they are three times larger. After He irradiation, the volume, in a moderate way, and the number of clusters increase for the $2 \AA \mathrm{Ni}$ layer whereas only the number of clusters increases for the $4 \AA$ Ni layer.

As a consequence, the intercluster distances are smaller after irradiation. The $l / D$ value (being $l / D$ as the intercluster distance and cluster diameter ratio) is $1.6-1.8$ for the asprepared samples that becomes in the 1.0-1.2 range for the irradiated ones. This reduction of the $l / D$ ratio may lead to magnetic cluster-cluster interaction. ${ }^{32}$

\section{Magnetic behavior}

As has been mentioned in the above discussion, two different kinds of samples can be distinguished: samples which show a continuous character in the Ni layer (corresponding to Ni layer thickness bigger than $10 \AA$ ) and samples in which metallic $\mathrm{Ni}$ appears in the form of clusters. The large continuous layers exhibit ferromagnetism, whereas the layers becoming discontinuous render superparamagnetic behavior. This is what is observed in the magnetic measurements shown in Fig. 6.

The samples with Ni layer thicknesses of 60 and $15 \AA$ although ferromagnetic in character present low $M_{s}$ values at $10 \mathrm{~K}$, about $30 \%$ of the bulk one for Ni that is $60 \AA$ thick and $12 \%$ for Ni that is $15 \AA$ thick. They are not explained by Ni diluted in $\mathrm{Si}_{3} \mathrm{~N}_{4}$ only since they represent $25 \%$ and $70 \%$ of the total amount of $\mathrm{Ni}$. Considering the $\mathrm{Ni}$ with metallic surrounding leads to an $M_{s}$ value of $184 \mathrm{emu} / \mathrm{cm}^{3}$ for both samples (Table III). The large roughness deduced from the EXAFS analysis has to be considered also to account for this strong reduction. With $\alpha=10$, effective thicknesses of 6 and $1.5 \AA$ mean that some regions of the Ni layers are no longer ferromagnetic. This is especially true if one takes into ac- count the possibility of magnetically dead atomic planes at the border with the $\mathrm{Si}_{3} \mathrm{~N}_{4}$ films as observed in the case of $\mathrm{Ni} / \mathrm{V}$ multilayers ${ }^{33}$ for instance.

Also, the magnetization behavior for the samples with 60 and $15 \AA$ of Ni is very different from the one of bulk Ni. There is a strong $M_{s}$ decrease with temperature, and saturation of $M_{s}$ is attained at $10 \mathrm{kOe}$ which is far bigger than the saturation field expected from the magnetocrystalline anisotropy (400 Oe). This can be explained assuming that together with large ferromagnetic regions there are also metallic clusters with a superparamagnetic behavior: small superparamagnetic clusters will saturate at high fields and, on increasing the temperature to $300 \mathrm{~K}$, the magnetization will be linear with the field.

For the thinnest layers of nominally 4 and $2 \AA$, Ni is mainly in the form of clusters. In order to fit the magnetic signal from $\mathrm{Ni}$ atoms in aggregates only, we have subtracted the paramagnetic contribution seen in the magnetization curves measured at room temperature of Fig. 7. The obtained curves are shown in Fig. 8 for the samples before and after irradiation with $\mathrm{He}$ and $\mathrm{P}$ (P fluence of $6.6 \times 10^{14}$ at. $/ \mathrm{cm}^{2}$ ). It must be mentioned that the values of magnetization in Fig. 8 are not corrected for the fraction of diluted $\mathrm{Ni}$ atoms as deduced after the analysis of the EXAFS data; when we take this fact into account, the $M_{s}$ values for the He-irradiated samples become $300 \mathrm{emu} / \mathrm{cm}^{3}$. Assuming that the Ni clusters are superparamagnetic at $10 \mathrm{~K}$, and that there is a distribution of cluster size $[f(N)]$, the magnetization curves, for the noninteracting case, can be described by a weighted superposition of Langevin functions:

$$
M(H)=M_{s} \int_{0}^{\infty} L\left(\mu H / k_{B} T\right) f(N) d N,
$$

where $\mu=N \mu_{\mathrm{B}}$ the magnetic moment of a single domain particle containing $\mathrm{N}$ atoms, $\mu_{B}$ the Bohr magneton associated with each atom, and $L\left(\mu_{T} H / k_{B} T\right)$ is the Langevin function.

We found that the weighting function that yielded a better fit was a Gaussian function in the number of particles centered at the origin. As can be seen in Fig. 6, the asprepared samples contain a small ferromagnetic contribution at $10 \mathrm{~K}$ that persists at $300 \mathrm{~K}$; this contribution has been taken into account in the fitting procedure by subtracting an appropriate function which resembles the ferromagnetic con- 

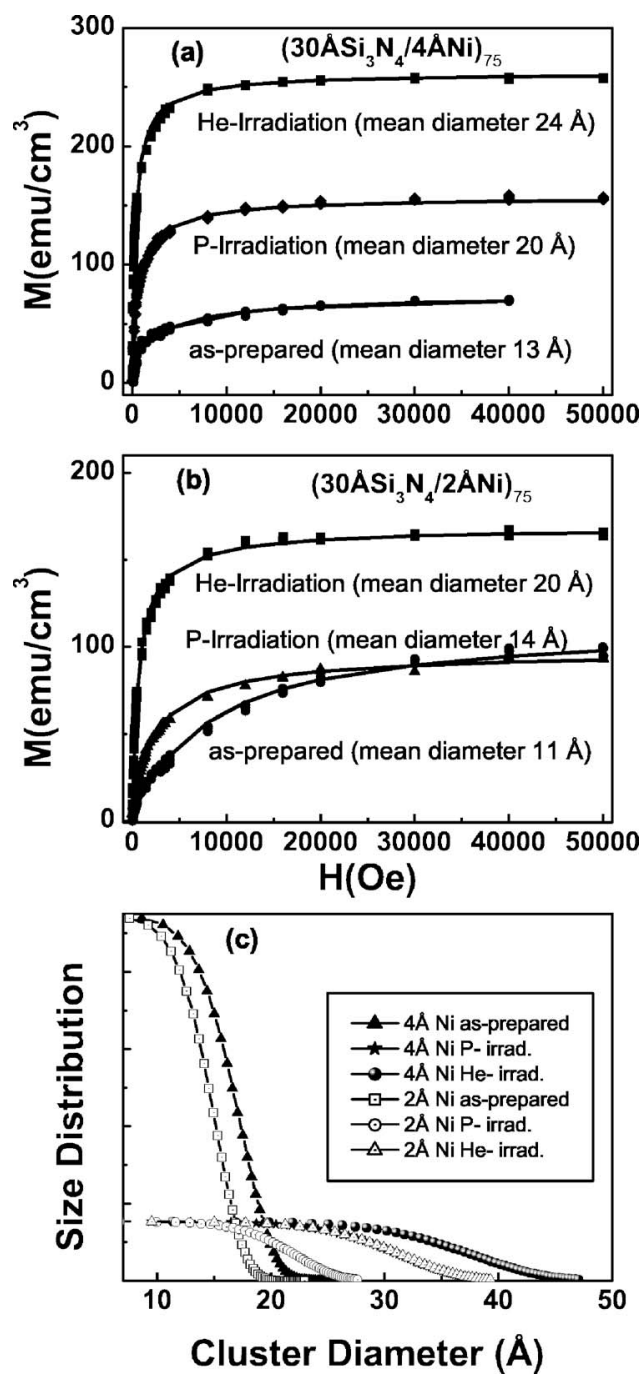

FIG. 8. [(a) and (b)] Data of Fig. 7 after subtracting the paramagnetic contribution. The continuous line corresponds to the Langevin fit for three different states of samples: as prepared, He irradiated, and P irradiated (fluence of $6.6 \times 10^{14}$ at. $/ \mathrm{cm}^{2}$ ). (c) Size distribution function obtained as the best fit for the above continuous lines.

tribution. We have found that the ferromagnetic contribution is $30 \%$ for the sample with a nominal layer thickness of $4 \AA$ and $4 \%$ for the sample with a nominal layer thickness of $2 \AA$.

The fit, shown as the solid lines in Fig. 8, provides the average diameter of the superparamagnetic particles; in this figure we show the average diameter obtained after each fit. The distribution of particle diameter is shown in Fig. 8(c); it can be seen that the effect of irradiation on particle size is to broaden the distribution. The atomic magnetic moment of $\mathrm{Ni}$ atoms in the clusters might be smaller than $0.6 \mu_{B}$. The cluster size obtained from magnetic measurements (Table III) in a totally independent way from the EXAFS analysis is in reasonable agreement with it. It is worth mentioning that the ferromagnetic contribution observed only in the as-prepared samples (especially in the one with a nominal layer thickness of $4 \AA$ ) is associated with large metallic regions, thus the average $\mathrm{Ni}-\mathrm{Ni}$ coordination number, which is what is measured in EXAFS, is bigger than the coordination number for nickel atoms in superparamagnetic clusters; since the cluster diameters in Tables I and II are deduced from average coor- dination numbers in the samples, these diameters are overestimated for the samples containing ferromagnetic contributions. This agreement validates the assumptions made in the modelization of the EXAFS analysis. As has been mentioned above, diluted $\mathrm{Ni}$ ions can be detected in the magnetic measurements as a constant slope in the $M(H)$ curves, after irradiation this slope diminishes accordingly with the modelization of the EXAFS analysis. Since the magnetic measurements have shown that the cluster diameters follow a particular distribution, it is possible to check whether this distribution is in accordance with the coordination numbers obtained with EXAFS; the average coordination number of a distribution of cluster diameter as obtained after magnetic measurements are shown in Table III; as can be seen the reasonable agreement validates the assumptions made in the modelization of the EXAFS analysis.

Regarding the disagreement between the predicted and calculated $M_{s}$ for these samples containing clusters, the presence of a dead magnetic layer at the surface of the cluster (as we have considered for the ferromagnetic samples) would yield a $M_{s}$ smaller than that obtained for the bulk Ni. In fact, it is observed that $M_{s}$ decreases for the samples where the cluster sizes drop.

\section{CONCLUSIONS}

Microstructural and magnetic characterizations have been reported for the multilayer-prepared $\mathrm{Ni}-\mathrm{Si}_{3} \mathrm{~N}_{4}$ system with the Ni thickness ranging from 2 to $60 \AA$. The samples were prepared by alternative sputtering deposition of $\mathrm{Ni}$ and $\mathrm{Si}_{3} \mathrm{~N}_{4}$. Two $\mathrm{Ni}$ thickness regimes must be distinguished. There is a Ni thickness range where the layers are rough but continuous and another Ni thickness range where $\mathrm{Ni}$ is forming clusters. The limit between these two regimes depends on the deposition rate and is of the order of 14-20 $\AA$. In all cases part of the $\mathrm{Ni}$ atoms is diluted in the $\mathrm{Si}_{3} \mathrm{~N}_{4}$ matrix and occupies Si sites.

Ion irradiations carried out on the thinnest $\mathrm{Ni}$ samples lead to a decrease of the amount of diluted $\mathrm{Ni}$ in agreement with the fact that such a site is thermodynamically unstable. Energy deposition in the form of electronic excitations is much more efficient is detrapping the $\mathrm{Ni}$ atoms from the $\mathrm{Si}_{3} \mathrm{~N}_{4}$ matrix. The average cluster size is not strongly modified but due to the larger number of metallic $\mathrm{Ni}$, the number of clusters increases and consequently the intercluster distance decreases.

The magnetic behavior of the samples is due to two contributions, one from the metallic and ferromagnetic $\mathrm{Ni}$ atoms and one from the $\mathrm{Ni}$ atoms diluted in $\mathrm{Si}_{3} \mathrm{~N}_{4}$, which display a paramagnetic character. For the samples with thin Ni layers, the metallic Ni clusters, with average size around $1 \mathrm{~nm}$ as determined by the EXAFS analysis, display a ferromagnetic character at low temperature. Loops at room temperature are well described by a superparamagnetic contribution that is significantly higher than the ferromagnetic one. The fits of the superparamagnetic hysteresis loops by using a Langevin function give cluster sizes in reasonable agreement with sizes evaluated by the EXAFS analyses.

Particular care has been taken in characterization of the 
Ni surrounding and interpretation of the Ni number of neighbors via XAS. This had allowed us to precisely follow the structural modifications induced by ion irradiation. The main result concerning this tool is that energy deposited in the form of electronic excitations is more efficient than nuclear collisions in driving the $\mathrm{Ni}$ atoms towards more stable crystallographic surroundings. Within the conditions used here, the result is Ni precipitation with an increase of the number of clusters and not a size increase as seen for instance in ripening process induced by thermal treatment.

Irradiation modifies the microstructure in a way that the amount of diluted Ni decreases strongly, which explains the observed reduction of the paramagnetic contribution. In these irradiation series, good agreement can be found when the cluster size is estimated based on the finite-size effect in the coordination number (evaluated by the EXAFS spectroscopy) and when the magnetic size is estimated from the analysis of the superparamagnetic hysteresis loop shape, using a Langevin function. The obtained cluster size diameters range from 10 to $23 \AA$.

\section{ACKNOWLEDGMENTS}

This work has been supported by the Spanish DGCYT under Contract No. MAT2003-06147-C04-02. We acknowledge the staff in charge of the DCI storage ring of LURE for beam time allocation, as well as to the European Large Installation program. We acknowledge the staff in charge of the IRMA and ARAMIS accelerators for their support during the ion-beam irradiation. Thanks are given to Professor $M$. García-Hernández for a critical reading of the manuscript, to Professor J. L. Martínez for his contribution to magnetic experiments, and to Dr. F. J. García-López from CNA at Sevilla for his help in the RBS experiments.

\section{APPENDIX}

In this appendix, we present a study of the average $\mathrm{CN}$ reduction due to the finite-size effect for a metallic spherical aggregate, which appears surrounded by a shell formed by a metal compound. The aim is to estimate the cluster size by using the CN obtained after the EXAFS analysis. In order to study the $\mathrm{Ni} / \mathrm{Si}_{3} \mathrm{~N}_{4}$ system, we have considered a model where clusters are formed by $\mathrm{Ni}$ atoms and by a covering shell formed by $\mathrm{Ni}-\mathrm{N}$ bonds. (It has been schematically represented in Fig. 9.)

For a cluster, as represented in Fig. 9, with the hypothesis that there are only $\mathrm{Ni}-\mathrm{Ni}$ first neighbor coordination in the clusters and only $\mathrm{Ni}-\mathrm{N}$ in the shell, the corresponding average $\mathrm{CN}$ can be written as follows:

$$
\begin{aligned}
\mathrm{CN}_{\mathrm{Ni}-\mathrm{Ni}} & =\frac{\left(\mathrm{CN}_{\mathrm{Ni}-\mathrm{Ni}}^{\text {bulk }} \times V_{R 1-d / 2}\right)+\left(\frac{1}{2} \mathrm{CN}_{\mathrm{Ni}-\mathrm{Ni}}^{\text {bulk }} \times V_{\text {surf }}\right)}{V_{R 2}}, \\
\mathrm{CN}_{\mathrm{Ni}-\mathrm{N}} & =\frac{\mathrm{CN}_{\mathrm{Ni}-\mathrm{N}}^{\text {bulk }} \times V_{\text {shell }}}{V_{R 2}},
\end{aligned}
$$

being $R 1$ and $R 2$ as the metallic core and whole cluster (core + shell) radius $R 2=R 1+S$ ), respectively. Equation (A1) is an

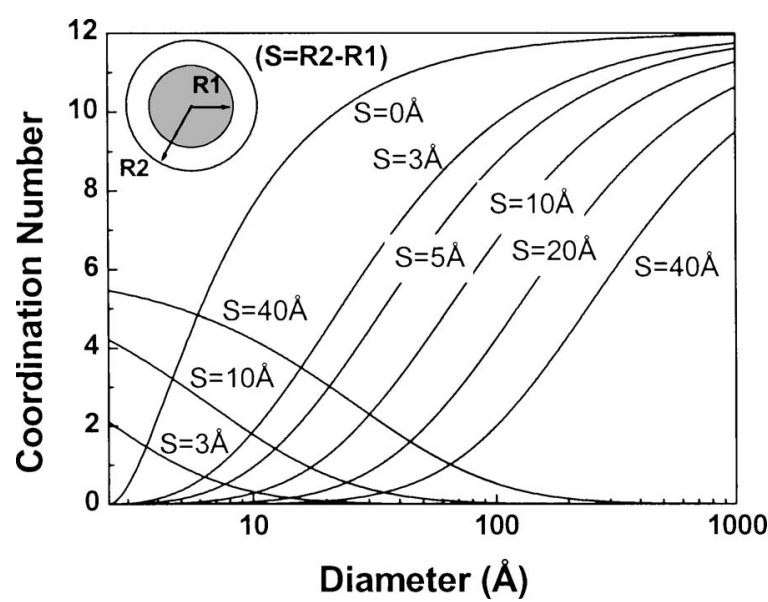

FIG. 9. Calculated Ni-Ni and Ni-N coordination numbers as a function of cluster diameter $(R 1)$, where the $S$ parameter is their shell thickness. The inset shows a schematic picture of an aggregate formed by a Ni core (soft gray) of $R 1$ radius surrounded by a Ni-N shell of thickness $S$.

expression similar to that appearing when the finite-size effect is modeled for spherical clusters, ${ }^{29}$ but $V_{R 2}$ refers to the volume of the sphere containing the whole cluster; $V_{R 1-d / 2}$ is the volume of the cluster core excluding a small portion near the surface with a thickness of one-half of the Ni-Ni distance ( $d$ is the diameter of $\mathrm{Ni}$ atoms); and $V_{\text {surf }}$ is the occupied volume of the atoms localized at the surface (core surface area by interatomic distance product). Equation (A2) reproduces only the relationship between the volume of the shell $\left(V_{\text {shell }}\right)$ and the volume of the whole cluster $\left(V_{R 2}\right)$.

For a fcc metal $\mathrm{CN}_{\mathrm{Ni}-\mathrm{Ni}}^{\text {bulk }}$ is 12 and, on the other hand, we have considered $\mathrm{CN}_{\mathrm{Ni}-\mathrm{N}}^{\text {bulk }}=6$ to reproduce a typical local ordering of $\mathrm{Ni}$ in an octahedral coordination. Figure 9(b) represents the behavior of both expressions of the $\mathrm{Ni}$ average $\mathrm{CN}$ for different thickness of the shell. By using this picture, it is possible to determine the cluster size for a system that follows this model. The EXAFS-determined $\mathrm{Ni}-\mathrm{Ni}$ and $\mathrm{Ni}-\mathrm{N}$ coordination number values should be matched on their corresponding curve at the same diameter value. The results of Table I cannot be interpreted within this graph, showing that our $\mathrm{Ni} / \mathrm{Si}_{3} \mathrm{~N}_{4}$ samples do not behave as a metallic Ni core surrounded by a $\mathrm{Ni}-\mathrm{N}$ covering shell. As a consequence of that, the EXAFS data must be explained in a different way, by considering the $\mathrm{Ni}-\mathrm{N}$ bonding as that obtained when $\mathrm{Ni}$ is diluted in the silicon nitride lattice by substituting the $\mathrm{Si}$ atoms.

${ }^{1}$ J. L. Simonds, Phys. Today 484, 24 (1995).

${ }^{2}$ F. A. Reuse and S. N. Khanna, Chem. Phys. Lett. 234, 77 (1995).

${ }^{3}$ I. M. L. Billas, A. Chatelain, and W. A. de Heer, Science 265, 1682 (1994).

${ }^{4}$ J. L. Dormann, Rev. Phys. Appl. 16, 275 (1981).

${ }^{5}$ A. E. Berkowitz, J. R. Mitchell, M. J. Carey, A. P. Young, S. Zhang, F. E. Spada, F. T. Parker, A. Hutten, and G. Thomas, Phys. Rev. Lett. 68, 3745 (1992).

${ }^{6}$ S. Yan, C. Ren, X. Wang, L. M. Mei, and H. Garmestani, Appl. Phys. Lett. 84, 2376 (2004)

${ }^{7}$ H. Ohno, Science 281, 951 (1998); T. Dietl, H. Ohno, F. Matsukura, J. Cibert, and D. Ferrand, ibid. 287, 1019 (2000).

${ }^{8}$ S. J. Pearton et al., J. Appl. Phys. 93, 1 (2003).

${ }^{9}$ S. Bourabad, A. Vega, M. J. López, P. Iñiguez, and J. A. Alonso, Phys. Rev. B 55, 13279 (1997). 
${ }^{10}$ D. Zanghi, C. M. Teodorescu, F. Petroff, H. Fischer, C. Bellouard, C. Clerc, C. Pélissier, and A. Traverse, J. Appl. Phys. 90, 6367 (2001).

${ }^{11}$ W. H. Flores, S. R. Teixeira, J. Geshev, J. B. M. da Cunha, P. J. Schilling, A. Traverse, and M. C. Martins-Alves, J. Magn. Magn. Mater. 188, 17 (1998).

${ }^{12}$ D. Zanghi, A. Delobbe, A. Traverse, and G. Krill, J. Phys.: Condens. Matter 10, 9721 (1998).

${ }^{13}$ M. Borowski, A. Traverse, and J. P. Dallas, J. Mater. Res. 10, 3136 (1995).

${ }^{14}$ D. Babonneau, F. Petroff, J. L. Maurice, F. Fettar, A. Vaurés, and A Naudon, Appl. Phys. Lett. 76, 2892 (2000).

${ }^{15}$ D. Zanghi, A. Traverse, F. Petroff, J. L. Maurice, A. Vaurés, and J. P. Dallas, J. Appl. Phys. 89, 6329 (2001).

${ }^{16}$ M. Vila, C. Prieto, and D. Cáceres, J. Appl. Phys. 94, 7868 (2003).

${ }^{17}$ M. Vila, C. Prieto, F. J. García-López, and M. A. Respaldiza, Nucl. Instrum. Methods Phys. Res. B 211, 199 (2003).

${ }^{18}$ M. Vila, F. Jiménez-Villacorta, C. Prieto, and A. Traverse, Phys. Scr. T115, 454 (2005).

${ }^{19}$ D. Zanghi, A. Traverse, S. Gautrot, and O. Kaïtasov, J. Mater. Res. 16, $512(2001)$

${ }^{20}$ A. Traverse, New J. Chem. 22, 677 (1998).

${ }^{21}$ J. Mimault, J. J. Faix, T. Girardeau, M. Jaouen, and G. Tourillon, Meas. Sci. Technol. 5, 482 (1994).
${ }^{22}$ K. V. Klementev, J. Phys. D 34, 209 (2001); VIPER for Windows is a freeware software at www.desy.de/ klmn/viper.html

${ }^{23}$ J. Mustre de Leon, J. J. Rehr, S. I. Zabinsky, and R. C. Albers, Phys. Rev. B 44, 4146 (1991).

${ }^{24}$ E. A. Stern, M. Qian, Y. Yacoby, S. M. Heald, and H. Maeda, Physica C 209, 331 (1993).

${ }^{25}$ H. Bernas et al. Nucl. Instrum. Methods Phys. Res. B 62, 416 (1992).

${ }^{26}$ J. Chaumont, F. Lalu, M. Salomé, and A. M. Lamoise, Nucl. Instrum. Methods Phys. Res. 189, 193 (1981).

${ }^{27}$ J. F. Ziegler, J. P. Biersack, and U. Littmark, The Stopping and Range of Ions in Solids (Pergamon, New York, 1986), Vols. I and II.

${ }^{28}$ C. Prieto, A. de Bernabé, R. Castañer, A. Muñoz-Martín, R. J. JiménezRioboó, M. García-Hernández, and A. de Andrés, J. Phys.: Condens. Matter 12, 2931 (2000).

${ }^{29}$ M. Boroswki, J. Phys. IV 7, 259 (1997).

${ }^{30}$ M. Kawamura, Y. Abe, and K. Sasaki, Vacuum 59, 721 (2000).

${ }^{31}$ J. C. Pivin, Nucl. Instrum. Methods Phys. Res. B 216, 239 (2004).

${ }^{32}$ A. Traverse and S. R. Teixeira, Structural and Magnetic Properties of Metallic Clusters Embedded in Matrices, Recent Research Development in Magnetism and Magnetic Materials Vol. 1 (Transworld Research Network, Trivandrum, 2003), p. 521.

${ }^{33}$ R. Krishnan, T. Catinaud, M. Seddat, M. Porte, and M. Tessier, J. Magn. Magn. Mater. 159, 175 (1996). 